\title{
Long-term nasal continuous positive airway pressure treatment lowers blood pressure in patients with obstructive sleep apnea regardless of age
}

\author{
Kensaku Aihara ${ }^{1}$, Kazuo Chin ${ }^{2}$, Toru Oga ${ }^{2}$, Ken-ichi Takahashi ${ }^{3}$, Takefumi Hitomi ${ }^{2}$, Misa Takegami $^{4}$, \\ Tomohiro Handa ${ }^{1}$, Akio Niimi ${ }^{1}$, Tomomasa Tsuboi ${ }^{2}$ and Michiaki Mishima ${ }^{1}$
}

Effective treatment with nasal continuous positive airway pressure (nCPAP) lowers blood pressure (BP) in patients with obstructive sleep apnea (OSA). It was reported that OSA might influence BP in middle-aged but not in elderly patients. However, effects of nCPAP treatment in elderly hypertensive OSA patients are not well known. We investigated long-term compliance with nCPAP and its effects on BP in elderly and middle-aged OSA patients. This observational study involved 92 OSA patients (81 men, 11 women; 46 middle-aged, 46 elderly; body mass index (BMI), 27.7 (27.0-28.7) $\mathrm{kg} \mathrm{m}^{-2}$; apnea hypopnea index, 43.0 (39.4-46.6) per $\mathrm{h}$; 95\% confidence intervals). BP and BMI were measured before the study and at two checkpoints after usage of nCPAP (616 (553-679) and 1048 (985-1114) days). Diastolic BP decreased by 5.69 (3.09-8.29) $\mathrm{mm} \mathrm{Hg}$ after 600 days of $\mathrm{nCPAP}$ treatment and by $4.50(1.80-7.19) \mathrm{mm} \mathrm{Hg}$ after 1000 days $(P=0.003)$. There were no significant changes in systolic BP, BMI or usage time of nCPAP. With a daily average of $3 \mathrm{~h}$ or more of $\mathrm{nCPAP}$ treatment, diastolic BP decreased significantly in subject groups $\geqslant 60$ and $<60$ years of age. Even in the elderly, a daily average use of $\mathrm{nCPAP}$ for $\mathbf{3} \mathrm{h}$ would lower diastolic BP in OSA patients.

Hypertension Research (2010) 33, 1025-1031; doi:10.1038/hr.2010.133; published online 29 July 2010

Keywords: compliance; diastolic blood pressure; elderly

\section{INTRODUCTION}

Obstructive sleep apnea (OSA) is strongly associated with hypertension. In the seventh report of the Joint National Committee on Prevention, Detection, Evaluation and Treatment of High Blood Pressure Education Program, OSA was defined as an identifiable cause of hypertension from numerous epidemiological data. ${ }^{1-3}$ Effects of nasal continuous positive airway pressure (nCPAP) on blood pressure (BP) in patients with OSA were variable in previous studies, but the net reduction in BP was significant compared with that in controls. ${ }^{4-6}$ In addition, the long-term effect of nCPAP treatment on BP has been shown..$^{7,8}$ Recently published meta-analyses ${ }^{9,10}$ suggested that effective nCPAP treatment indeed lowers BP in patients with OSA, but age-related differences in the effects of nCPAP treatment on $\mathrm{BP}$ remain to be elucidated.

The combination of systolic and diastolic hypertension is common in middle-aged hypertensive patients, whereas isolated systolic hypertension is predominantly a disease of elderly hypertensive patients. ${ }^{11}$ Systolic/diastolic hypertension represents multiple etiologic factors, with evidence to suggest that the sympathetic nervous system is an important mediator. ${ }^{12}$ Meanwhile, isolated systolic hypertension results from the age-dependent loss of arterial compliance..$^{13}$ Because it is known that nCPAP attenuates the increase in sympathetic activity in OSA, ${ }^{14}$ the effectiveness of nCPAP treatment may differ between elderly and middle-aged persons with OSA. Haas et al..$^{15}$ showed that sleep-disordered breathing (SDB) was associated with systolic/diastolic hypertension in persons aged 40-59 years, but there was neither a significant nor consistent relationship between hypertension and SDB among those more than 60 years of age. This age-related difference may reflect different underlying pathophysiological processes. However, a relatively low proportion $(20.7 \%)$ of participants aged $\geqslant 60$ years had study results showing at least moderate SDB (apnea hypopnea index $(\mathrm{AHI}) \geqslant 15)$ but the effects of nCPAP treatment were not investigated. Therefore, it is important to evaluate age-related differences in the effects of nCPAP treatment on BP in patients with OSA.

We hypothesized that long-term nCPAP treatment with sufficient usage time lowers BP in elderly as well as in middle-aged hypertensive OSA patients. Thus, we investigated long-term compliance with nCPAP and its effects on BP in elderly and middle-aged OSA patients.

\footnotetext{
${ }^{1}$ Department of Respiratory Medicine, Kyoto University Graduate School of Medicine, Sakyo-ku, Kyoto, Japan; ${ }^{2}$ Department of Respiratory Care and Sleep Control Medicine, Kyoto University Graduate School of Medicine, Sakyo-ku, Kyoto, Japan; ${ }^{3}$ Department of Respiratory Medicine, Otsu Red Cross Hospital, Otsu, Shiga, Japan and ${ }^{4}$ Department of Epidemiology and Healthcare Research, Kyoto University Graduate School of Medicine and Public Health, Sakyo-ku, Kyoto, Japan

Correspondence: Dr K Chin, Department of Respiratory Care and Sleep Control Medicine, Kyoto University Graduate School of Medicine, 54 Shogoin Kawahara-cho, Sakyo-ku, Kyoto 606-8507, Japan.

E-mail: chink@kuhp.kyoto-u.ac.jp

Received 25 December 2009; revised 30 March 2010; accepted 17 May 2010; published online 29 July 2010
} 


\section{METHODS}

\section{Study subjects}

The medical ethics committee at our institution reviewed and approved the study. All participants provided informed consent. In Japan, according to health insurance rules, patients with OSA who use nCPAP under the health insurance system must come to the hospital every month and pay a medical fee at each visit. We enrolled 101 outpatients with OSA who were consecutively seen in our hospital and who had been using nCPAP continuously for more than 3 years and who came to our hospital every month. Nine patients were excluded from analysis because of change in medication during the observation period. A total of 92 patients who received the same medical regimen (including antihypertensive medications) beginning 1 month before the start of this study and throughout the study were investigated. Tobacco and alcohol consumption did not change during the study. Because these participants included 66 patients who had been enrolled in a previous study ${ }^{7}$ that investigated compliance with long-term nCPAP treatment and its effect on $\mathrm{BP}$, polysomnography for all the OSA patients was performed by the same methods as in our previous studies. ${ }^{7,16,17}$ The amplitude of airflow was monitored by thermistors (Nihon Kohden, Tokyo, Japan) that were placed at the nose and the mouth. Apnea was defined as the complete cessation of airflow and hypopnea as a clear reduction in airflow or abdominal excursion lasting for $10 \mathrm{~s}$ or more, accompanied by a decrease in oxygen saturation of at least $3 \%{ }^{7,16,17,18}$ The number of episodes of apnea and hypopnea per hour was defined as the AHI. Each of the OSA patients had an AHI of 20 or more, because the health insurance system in Japan covers nCPAP only if the AHI is 20 or more. Following a diagnostic sleep study the patients underwent CPAP titration via standard polysomnography with manual control. To investigate smoking history, we calculated the Brinkman index by the following formula:

Brinkman index $=$ number of cigarettes smoked per day $\times$ number of smoking years

\section{Study design}

We performed a retrospective study of a cohort of patients with OSA who had used nCPAP continuously for more than 3 years to investigate the long-term effects of nCPAP treatment on BP in elderly and middle-aged OSA patients. In this study, to compare the results with that of Haas et al.,15 'elderly' was defined as the age 60 or over. After OSA patients had undergone 3 years of nCPAP treatment, we examined their medical charts. We obtained information about each patient's nCPAP treatment almost every month in the outpatient department of our hospital, and also obtained other data such as for body weight and $\mathrm{BP}^{7}$ This information was gathered at two time points as close as possible to a yearly interval (616 (553-679) and 1048 (985-1114) days).

\section{Epworth Sleepiness Scale}

The Epworth Sleepiness Scale ${ }^{19}$ was administered before nCPAP treatment in 92 patients with OSA. With the Epworth Sleepiness Scale, individuals score themselves on a scale of 0 (not at all likely to fall asleep) to 3 (very likely to fall asleep) according to how easily they would fall asleep in eight situations, with possible overall scores of $0-24$. The higher the score is, the sleepier the individual is.

\section{Blood pressure and body weight}

Patients' BP and body weight were measured before the study and every month after treatment had begun. The resting BP was measured in the right arm after a 5-min rest using a conventional mercury sphygmomanometer. ${ }^{20}$ The first and last Korotkoff sounds were used to determine systolic and diastolic BP, respectively. The average of the second and third of three consecutive measurements was used as the BP value for the month. Weight was measured on a portable scale with the subject wearing light clothes. These BP and weight measurements are standard practice at our respiratory medicine clinic. Each parameter at two checkpoints was calculated by the mean value over 3 months.

Hypertension was defined as a systolic pressure above $140 \mathrm{~mm} \mathrm{Hg}$ or a diastolic pressure above $90 \mathrm{~mm} \mathrm{Hg}$. Patients taking any antihypertensive medication were classified hypertensive.

\section{Compliance with nCPAP treatment}

We checked compliance using the nCPAP machine, based on data that were taken from the regular examination of the machine every 1 or 2 years. Compliance data on the daily average time (h per day) of usage of the nCPAP apparatus were acquired by reading the time counter in each nCPAP machine. To determine the average daily usage that was sufficient to lower BP of the OSA patients, we compared baseline diastolic BP values with those at the second checkpoint according to various intervals of usage. Usage was evaluated according to 30 -min increments as follows: $<30 \mathrm{~min}, 30 \mathrm{~min}, 1 \mathrm{~h}, 90 \mathrm{~min}$, $2 \mathrm{~h}, 150 \mathrm{~min}, 3 \mathrm{~h}$ and so on. After identifying the minimum number of hours that were needed to lower BP significantly, we assigned patients to a 'good compliance group' if they used nCPAP an average of that minimum time or more; those who used nCPAP less were assigned to the 'poor compliance group'.

\section{Statistical analysis}

All statistical analyses were performed using nonparametric tests with statistical software (StatView version 5.0 for Windows; Abacus Concepts, Berkeley, CA, USA). Differences between the two groups were compared with the MannWhitney $U$-test. Differences between any two conditions in OSA patients were compared with the Wilcoxon signed-rank test. When more than two conditions were compared, a significant difference was tested among all of the conditions by the Friedman test. Correlations between variables were analyzed by the Spearman's rank correlation test. A $P$-value $<0.05$ was considered statistically significant. The data are expressed as the mean ( $95 \%$ confidence interval).

\section{RESULTS}

\section{Effects on blood pressure}

Table 1 shows the characteristics of patients according to age group before nCPAP. When both groups are considered together, these patients had a mean AHI of 43.0 (39.4-46.6). All received nCPAP with an adequate pressure of $9.3(8.8-9.8) \mathrm{cm} \mathrm{H}_{2} \mathrm{O}$. nCPAP treatment reduced the patients' AHI to a mean of $2.1(1.6-2.6)(P<0.0001)$. The mean Epworth score for the 92 subjects was 9.5 (8.4-10.6). Among the 92 patients with OSA, 68 had hypertension and 19 had diabetes mellitus. Forty-seven of the patients with hypertension took medication. Thirty-six patients were receiving a calcium inhibitor, twentyfour an angiotensin II receptor antagonist, six an $\alpha$-blocker, seven a $\beta$-blocker, eight a diuretic drug and seven a nitrous drug. Thirteen patients were taking three or more antihypertensive drugs. In the older group, six patients had a history of stroke and two patients had a history of myocardial infarction before nCPAP treatment. After longterm nCPAP treatment, the diastolic BP in OSA patients significantly decreased whereas the systolic BP did not (Table 2). Diastolic BP decreased by $5.69(3.09-8.29) \mathrm{mm} \mathrm{Hg}$ after 600 days of nCPAP treatment and by $4.50(1.80-7.19) \mathrm{mm} \mathrm{Hg}$ after 1000 days of nCPAP treatment $(P=0.003)$. The body mass index $(\mathrm{BMI})$ did not change significantly during the treatment period nor did usage time of nCPAP. The diastolic BP decreased in 59 out of the 92 patients. However, the degree of decrease in diastolic BP did not significantly correlate with age, BMI or the Brinkman index. Moreover, the degree of improvement in AHI, the lowest arterial oxygen saturation during sleep and the percentage of time spent at less than $90 \%$ arterial saturation also did not significantly correlate with the degree of decrease in diastolic BP.

\section{Age-related differences}

In accordance with a previously reported procedure, ${ }^{15}$ we divided OSA patients into two age groups: those $\geqslant 60$ years of age and those $<60$ years of age (Table 1 ). There were 81 men and 11 women with a mean age of 55.6 (53.0-58.0) years and BMI of 27.9 (27.0-28.7) $\mathrm{kg} \mathrm{m}^{-2}$. The number in each group was the same $(n=46)$. There were no differences in sex, nCPAP usage time, heart rate and BP between 
Table 1 Comparison of characteristics of patients with OSA before usage of nCPAP grouped according to age

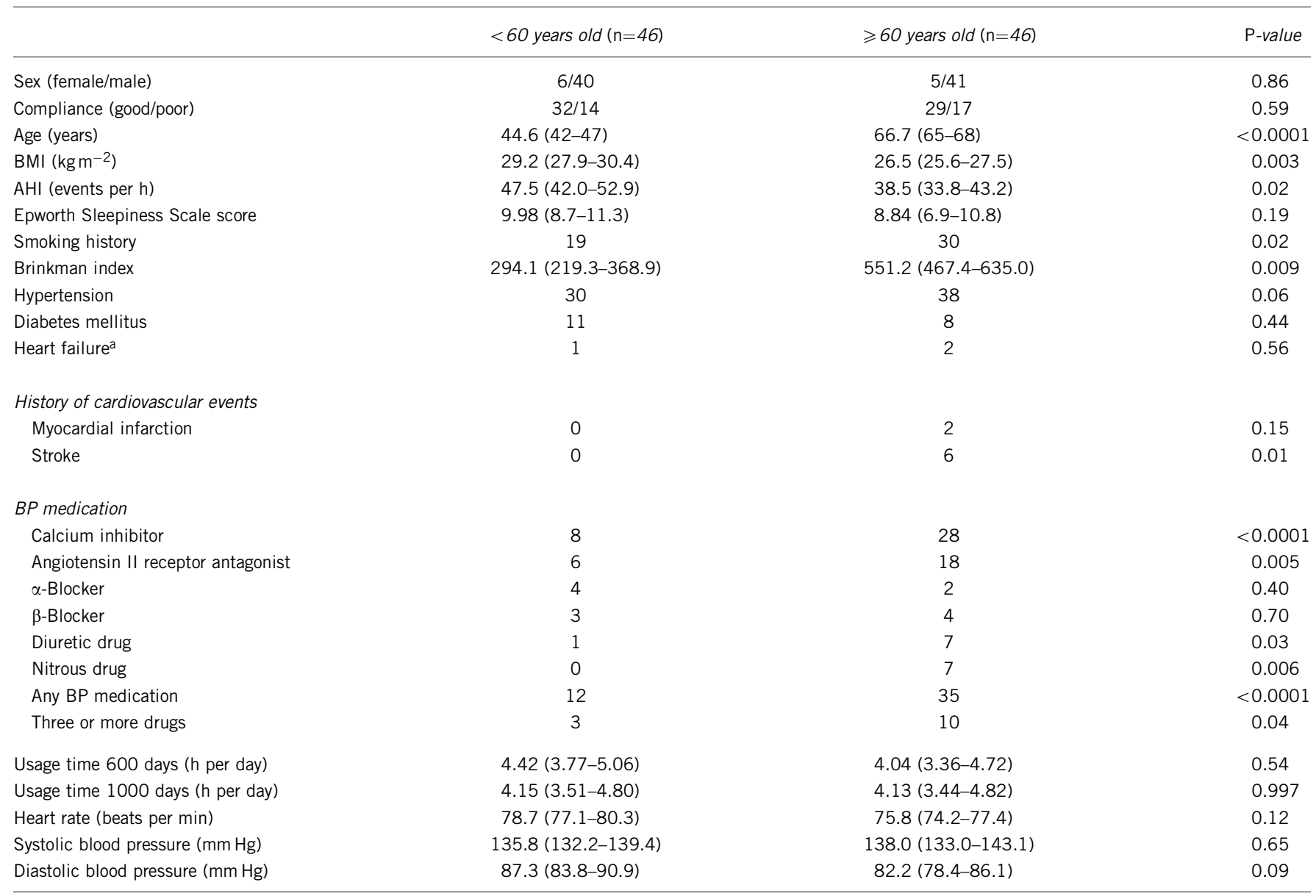

Abbreviations: AHI, apnea hypopnea index; BMI, body mass index; BP, blood pressure.

Data presented as mean ( $95 \%$ confidence interval).

aDiagnosis was based on information from medical charts.

Table 2 Selected characteristics in 92 patients with OSA before and after nCPAP treatment

\begin{tabular}{lccc}
\hline & Before nCPAP & After 600 days of nCPAP & After 1000 days of nCPAP \\
\hline BMI ( $\mathrm{kg} \mathrm{m}^{-2}$ ) & $27.9(27.0-28.7)$ & $27.5(26.5-28.4)$ & $27.3(26.3-28.2)$ \\
Usage time (h per day) & & $4.23(3.77-4.69)$ & $4.14(3.68-4.60)$ \\
Systolic blood pressure $(\mathrm{mm} \mathrm{Hg})$ & $136.9(133.8-140.0)$ & $133.0(130.9-134.9)$ & $133.3(130.9-135.7)$ \\
Diastolic blood pressure $(\mathrm{mm} \mathrm{Hg})$ & $84.8(82.2-87.4)$ & $78.8(76.5-81.1)$ & 0.08 \\
\hline
\end{tabular}

Abbreviations: BMI, body mass index; nCPAP, nasal continuous positive airway pressure.

Data presented as mean ( $95 \%$ confidence interval).

groups. The percentage of smokers was greater in the older group than in the younger group. The majority $(82.6 \%)$ of the older participants were classified as being hypertensive compared with $65.2 \%$ of the younger group. Approximately three quarters (76.1\%) of the older participants were taking antihypertensive medications compared with $26.1 \%$ of the younger participants. There were also more patients taking three or more antihypertensive drugs in the older group than in the younger group $(P=0.04)$. BMI and AHI were significantly lower in the older group than in the younger group.

Figure 1 shows the changes in BP according to age group after longterm nCPAP treatment. Diastolic BP decreased significantly in both age groups after 1000 days of nCPAP treatment $(P=0.01,<60$ years of age; $P=0.02, \geqslant 60$ years of age). The degrees of decrease in diastolic BP did not differ significantly between the older and the younger groups ( $P=0.43$, before 600 days; $P=0.69$, before 1000 days). There were no differences in body weight $(P=0.23,<60$ years of age; $P=0.16, \geqslant 60$ years of age) and nCPAP usage time $(p=0.58,<60$ years of age; $P=0.98, \geqslant 60$ years of age) in both age groups during the study period.

Blood pressure and compliance

When usage times were checked according to 30 -min intervals to determine the minimum number of hours that were needed to lower BP significantly, a significant decrease in diastolic BP (7.7 (4.5-10.8) $\mathrm{mm} \mathrm{Hg}, P<0.0001, n=61)$ was achieved by a daily average of at least $3 \mathrm{~h}$ of nCPAP treatment. However, nCPAP usage time per se was not 

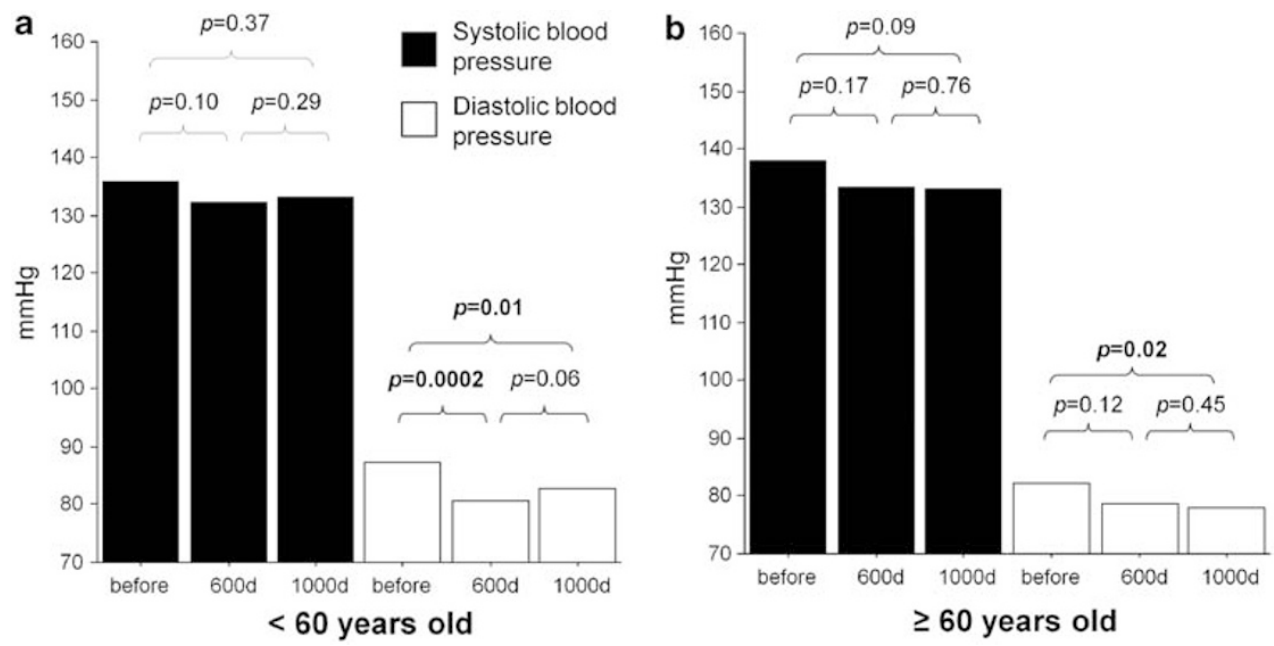

Figure 1 Mean systolic and diastolic blood pressure values in patients aged $<60$ years $(n=46$, (a)) and patients aged $\geqslant 60$ years ( $n=46$, (b)) before nasal continuous positive airway pressure (nCPAP) treatment and after 600 and 1000 days of nCPAP treatment.

Table 3 Baseline characteristics of patients with OSA with either good or poor compliance with nCPAP

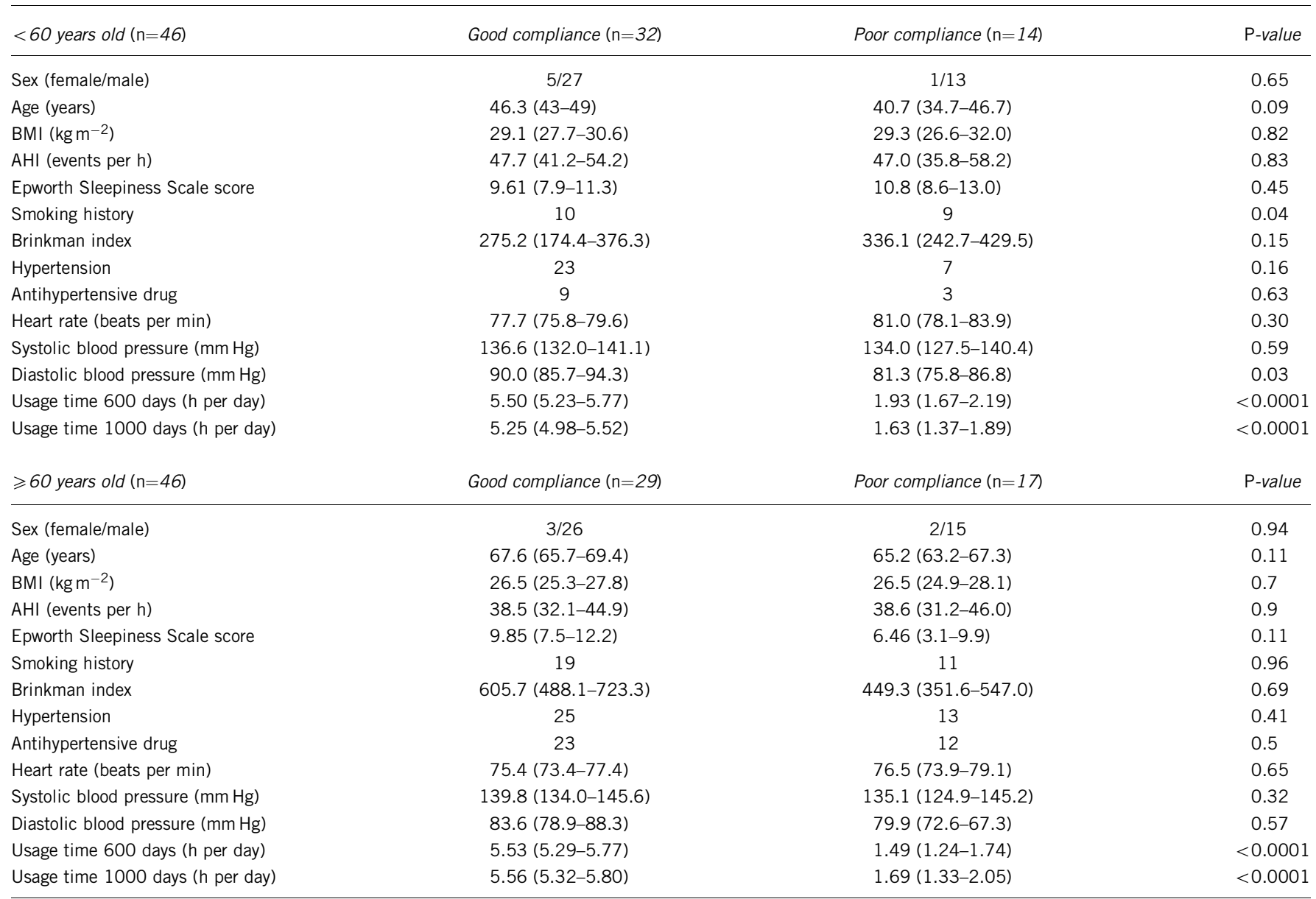

Abbreviations: $\mathrm{AHI}$, apnea hypopnea index; BMI, body mass index.

Data presented as mean ( $95 \%$ confidence interval).

significantly correlated with the degree of decrease in diastolic BP. A total of 61 patients used nCPAP for a daily average of $3 \mathrm{~h}$ or more (good compliance group) and 31 patients used nCPAP $<3 \mathrm{~h}$ daily (poor compliance group). We further divided the age groups into those with good compliance and poor compliance (Table 3). Differences in sex, age, BMI or AHI between the good and poor compliance groups were not significant. Diastolic BP decreased significantly in both age groups with good compliance, but not in either age group 

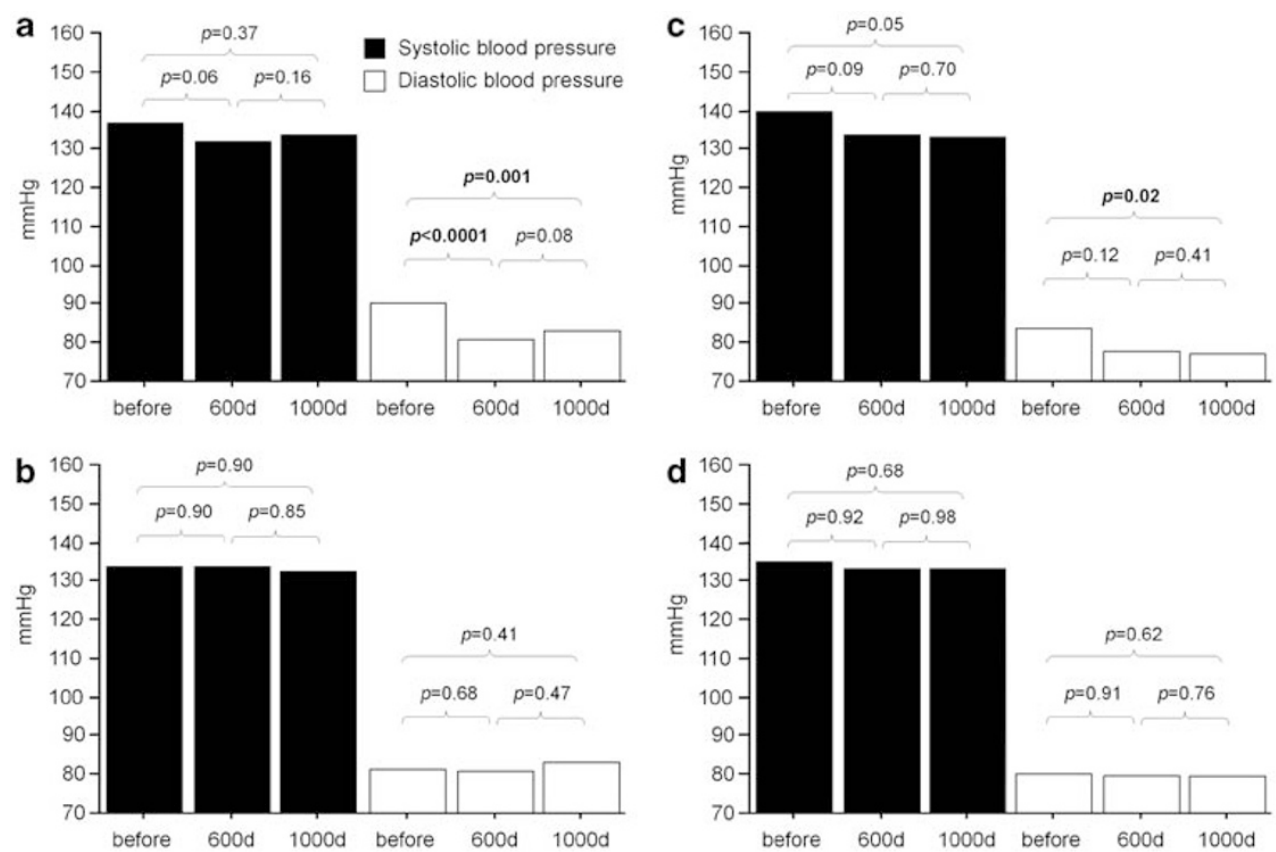

Figure 2 Mean systolic and diastolic blood pressure values in patients aged $<60$ years with good compliance $(n=32$, (a)), aged $<60$ years with poor compliance $(n=14,(\mathbf{b}))$, aged $\geqslant 60$ years with good compliance $(n=29,(\mathbf{c}))$ and aged $\geqslant 60$ years with poor compliance $(n=17$, (d)) before nasal continuous positive airway pressure (nCPAP) treatment and after 600 and 1000 days of nCPAP treatment.

having poor compliance. Systolic BP did not change in any group (Figure 2). The degree of decrease in diastolic BP did not differ significantly between the older and younger groups with good compliance $(P=0.27$, before 600 days; $P=0.87$, before 1000 days $)$.

\section{DISCUSSION}

This study showed that long-term nCPAP treatment lowered diastolic BP not only in middle-aged OSA patients but also in elderly OSA patients. To achieve a significant effect on diastolic BP, we required an average daily usage of nCPAP for $3 \mathrm{~h}$, which was consistent with our previous report. ${ }^{7}$ With that level of compliance, diastolic BP in elderly hypertensive OSA patients decreased significantly. However, as noted above, nCPAP usage time per se did not significantly correlate with the degree of decrease in diastolic BP. It has been reported that mean usage time of nCPAP was positively but not significantly correlated with mean net change in $\mathrm{BP}(P=0.13) .{ }^{10}$ Thus, the effects of nCPAP treatment would be affected by not only usage time but also other factors such as the arousal index or daily sleep time. Several studies have explored the impact of nCPAP treatment on BP. ${ }^{4-6}$ These studies included older adults, but uncertainty has remained regarding longterm effects of nCPAP treatment in elderly hypertensive OSA patients, likely attributable to the level of severity of OSA, sample size and duration of intervention. Although it was reported that OSA might not influence BP in elderly patients, ${ }^{15}$ the present study clearly showed for the first time that long-term nCPAP treatment with good compliance lowered diastolic BP in elderly OSA patients.

The combination of systolic/diastolic hypertension is common in middle-aged hypertensive patients, whereas isolated systolic hypertension is predominately a disease of elderly hypertensive patients. ${ }^{11}$ Systolic/diastolic hypertension represents multiple etiologic factors, with evidence to suggest that the sympathetic nervous system is an important mediator. ${ }^{12}$ Meanwhile, isolated systolic hypertension results from age-dependent arterial wall thickening and stiffness and endothelial dysfunction. ${ }^{13}$ Activation of the sympathetic nervous system is an important mechanism linking OSA to hypertension, ${ }^{21,22}$ and nCPAP attenuates the increase in sympathetic activity in OSA. ${ }^{14}$ Therefore, the potential mechanisms linking OSA to hypertension and the effectiveness of nCPAP treatment may be different in elderly patients than in middle-aged patients.

In this study, long-term nCPAP treatment lowered diastolic BP but not systolic BP. Although some studies have reported a decrease in systolic and diastolic BP, most of the trials in those meta-analyses were composed of mainly normotensive patients. ${ }^{9,10}$ In the present study, approximately three quarters $(73.9 \%)$ of the participants had hypertension and nearly half of the participants were taking antihypertensive medication. From our previous study, ${ }^{7}$ both systolic and diastolic $\mathrm{BP}$ were lowered by a daily average of $3 \mathrm{~h}$ of nCPAP treatment in hypertensive OSA patients who were not taking any antihypertensive medication, while nCPAP treatment lowered diastolic BP alone in such patients being administered antihypertensive medications. This difference in study population might affect the results. In addition, Davies et al. ${ }^{23}$ reported that, compared with closely matched control subjects, patients with OSA had increased ambulatory diastolic BP during both day and night but had increased systolic BP only at night. Because we did not perform ambulatory BP monitoring, we might have overlooked a decrease in systolic BP at night. Therefore, OSA may predominantly raise diastolic BP in hypertensive OSA patients.

This study also showed that long-term sufficient nCPAP usage, that is, $3 \mathrm{~h}$ or longer daily, is effective in lowering BP in both middle-aged and elderly hypertensive OSA patients and that the degree of decrease in diastolic BP did not differ significantly between age groups. Therefore, differences in etiologies of hypertension between middleaged and elderly OSA patients might not be great enough to create obvious differences in effectiveness of nCPAP. However, statistical significance in the drop in diastolic BP was not observed at 600 days but was seen at 1000 days of nCPAP treatment in elderly patients. Although we cannot rule out the possibility that the sample size was insufficient to confirm a significant decrease in diastolic BP at 600 
days, diastolic BP of the elderly OSA patients might have gradually decreased through nCPAP treatment and, due to age-related differences in the mechanisms linking OSA to hypertension, an additional investment of time might be required to see significant decreases in BP in elderly patients. Although we did not evaluate sympathetic nerve activity or arterial compliance in the participants in this study, some reversible factors may have been present that could be gradually improved by nCPAP even in elderly hypertensive OSA patients. For instance, some studies ${ }^{24,25}$ have shown that BP decreased after nCPAP treatment in patients with heart failure and OSA, suggesting that decreased cardiac load may also contribute to the decrease in BP observed in elderly patients. Although we did not monitor cardiac function of the participants using echocardiography before and during the study, there might be more patients with heart failure among the older participants because a significantly greater number of the older participants were taking diuretics than were the younger participants (Table 1).

There is a higher prevalence of SDB in the elderly than in middleaged adults. $^{26,27}$ But elderly individuals with OSA experience less daytime sleepiness than younger patients with this disorder, ${ }^{28,29}$ and partially as a result they are less motivated to be adherent to nCPAP treatment. ${ }^{28}$ Moreover, a randomized sham-placebo-controlled, crossover study ${ }^{30}$ showed no significant fall in 24-h mean BP in patients with nonhypersomnolent hypertensive OSA after 1 month of nCPAP treatment. Also in the present study, the mean score on the Epworth Sleepiness Scale in the elderly OSA patients was 8.84 (6.9-10.8), which was lower than that of middle-aged patients although it was not significant. However, long-term nCPAP treatment lowered diastolic BP in elderly OSA patients with good compliance despite a lack of hypersomnolence. In addition, a prospective cohort study showed a significantly high mortality risk from untreated SDB, irrespective of symptoms of sleepiness. ${ }^{31}$ Therefore, it is important to find occult OSA in the elderly and to treat it with nCPAP.

Haas et al. ${ }^{15}$ showed that SDB was associated with systolic/diastolic hypertension in persons aged 40-59 years, but that there was neither a significant nor consistent relationship between hypertension and SDB among those more than 60 years of age. But results of the present study showed a significant diastolic BP decrease in both those who were $\geqslant 60$ and $<60$ years of age, and the degrees of decrease in diastolic BP were not significantly different between the two groups. It might be thought that the difference in severity of OSA in the participants between the two studies affected the results. The AHI of each OSA patient was 20 or more and the mean AHI of the patients aged $\geqslant 60$ years was $38.5(33.8-43.2)$ in this study, whereas a relatively low proportion $(20.7 \%)$ of participants aged $\geqslant 60$ years had at least moderate SDB $(\mathrm{AHI} \geqslant 15)$ in the study by Haas et al.

The main limitation of this study was its retrospective uncontrolled design. However, conducting a prospective controlled study over such a long time period presents an ethical dilemma, because long-standing uncontrolled hypertension could affect the patients' prognosis through possible cardiovascular events. The second point was the difference in BMI and AHI between OSA patients $\geqslant 60$ and $<60$ years of age. The degree of response to nCPAP treatment may depend on the severity of OSA. However, the degree of decrease in diastolic BP did not significantly correlate with BMI or the degree of improvement in AHI. Third, although the number of participants classified as hypertensive was not statistically different between the two age groups, a significantly greater number of the older participants were taking three or more antihypertensive medications than the younger participants. Therefore, there might be more patients with difficult-to-control hypertension that responded to nCPAP treatment among the older patients. The role of nCPAP in patients with difficult-to-control hypertension has been analyzed. ${ }^{32,33}$ Both studies found a significant decrease in systolic BP, particularly at night after several months of nCPAP treatment, whereas the decrease in diastolic BP was not statistically significant either at night or during the day. However, we found a significant decrease in diastolic but not in systolic BP during daytime. Although differences in the mechanisms whereby nCPAP treatment lowered BP of the participants between these studies and our study are unclear, the decrease in diastolic BP in our present study may not be related to difficult-to-control hypertension. Fourth, we did not use the latest American Academy of Sleep Medicine manual for the scoring of sleep and associated events and hypopnea was measured by thermistors because all the participants of this study had undergone diagnostic polysomnography before 2006. Therefore, if the latest criteria and an airflow pressure sensor were used, the hypopnea index might have differed from that shown presently. However, although these differences could affect the data on the AHI of the participants they would not have influenced the effectiveness of sufficient nCPAP treatment for BP. Finally, we did not perform ambulatory BP monitoring. It is well known that ambulatory BP monitoring is a better predictor of cardiovascular events than office BP measurements. ${ }^{34,35}$ Therefore, to estimate usual BP and minimize the difference in clinical implications between the office BP and ambulatory $\mathrm{BP}$, we averaged the second and third of three consecutive measurements as the BP value for each of the 3 monthly visits that are usual for nCPAP patients. Then the BP values for the two checkpoints (600 and 1000 days) were derived from the mean value of 3 monthly clinic visits closest to each of the two checkpoint periods. Although randomized controlled trials have examined the effect of nCPAP treatment for OSA on BP using office BP measurements, ${ }^{36,37}$ further study is needed to confirm our findings by ambulatory BP monitoring.

Treatment of hypertension is critically important for the care of older adults who are particularly vulnerable to cardiovascular events. From large prospective studies, a BP fall of $3.3 \mathrm{~mm} \mathrm{Hg}$ would be expected to be associated with a $20 \%$ stroke and $15 \%$ coronary heart disease event risk reduction. ${ }^{38}$ Thus, the BP falls observed with nCPAP treatment represent the potential for significant reductions in vascular risk. The current study results showed that long-term nCPAP treatment lowered diastolic BP in not only middle-aged subjects with OSA but also in elderly patients with OSA. To achieve a significant effect on diastolic BP, daily average usage of nCPAP for $3 \mathrm{~h}$ is needed. It is noteworthy that elderly OSA patients used nCPAP treatment over the long-term with good compliance.

Hypertension has numerous etiologies, especially in the elderly. In addition, elderly OSA patients often lack typical clinical symptoms. Even in elderly hypertensive patients, we should consider the possibility of underlying OSA, which is treatable with sufficient nCPAP treatment.

\section{CONFLICT OF INTEREST}

The authors declare no conflict of interest.

1 Chobanian AV, Bakris GL, Black HR, Cushman WC, Green LA, Izzo Jr JL, Jones DW, Materson BJ, Oparil S, Wright Jr JT, Roccella EJ. Seventh report of the Joint National Committee on Prevention, Detection, Evaluation, and Treatment of High Blood Pressure. Hypertension 2003; 42: 1206-1252.

2 Nieto FJ, Young TB, Lind BK, Shahar E, Samet JM, Redline S, D’Agostino RB, Newman $A B$, Lebowitz MD, Pickering TG. Association of sleep-disordered breathing, sleep apnoea, and hypertension in a large community-based study. Sleep Heart Health Study. JAMA 2000; 283: 1829-1836. 
3 Peppard PE, Young T, Palta M, Skatrud J. Prospective study of the association between sleep-disordered breathing and hypertension. N Engl J Med 2000; 342: 1378-1384.

4 Faccenda JF, Mackay TW, Boon NA, Douglas NJ. Randomized placebo-controlled trial of continuous positive airway pressure on blood pressure in the sleep apnoea-hypopnoea syndrome. Am J Respir Crit Care Med 2001; 163: 344-348.

5 Pepperell JC, Ramdassingh-Dow S, Crosthwaite N, Mullins R, Jenkinson C, Stradling JR, Davies RJ. Ambulatory blood pressure after therapeutic and subtherapeutic nasal continuous positive airway pressure for obstructive sleep apnoea: a randomised parallel trial. Lancet 2002; 359: 204-210.

6 Becker HF, Jerrentrup A, Ploch T, Grote L, Penzel T, Sullivan CE, Peter JH. Effect of nasal continuous positive airway pressure treatment on blood pressure in patients with obstructive sleep apnoea. Circulation 2003; 107: 68-73.

7 Chin K, Nakamura T, Takahashi K, Sumi K, Matsumoto H, Niimi A, Fukuhara S, Mishima M, Nakamura T. Falls in blood pressure in patients with obstructive sleep apnoea after long-term nasal continuous positive airway pressure treatment. J Hypertens 2006; 24: 2091-2099.

8 Campos-Rodriguez F, Perez-Ronchel J, Grilo-Reina A, Lima-Alvarez J, Benitez MA, Almeida-Gonzalez C. Long-term effect of continuous positive airway pressure on $\mathrm{BP}$ in patients with hypertension and sleep apnoea. Chest 2007; 132: 1847-1852.

9 Haentjens P, Van Meerhaeghe A, Moscariello A, De Weerdt S, Poppe K, Dupont A, Velkeniers $B$. The impact of continuous positive airway pressure on blood pressure in patients with obstructive sleep apnoea syndrome: evidence from a meta-analysis of placebo-controlled randomized trials. Arch Intern Med 2007; 167: 757-764.

10 Bazzano LA, Khan Z, Reynolds K, He J. Effect of nocturnal nasal continuous positive airway pressure on blood pressure in obstructive sleep apnoea. Hypertension 2007; 50: 417-423.

11 National High Blood Pressure Education Program Working Group. National High Blood Pressure Education Program Working Group Report on hypertension in the elderly. Hypertension 1994; 23: 275-285.

12 Esler M, Rumantir M, Kaye D, Jennings G, Hastings J, Socratous F, Lambert G. Sympathetic nerve biology in essential hypertension. Clin Exp Pharmacol Physiol 2001; 28: 986-989.

13 Lakatta EG, Levy D. Arterial and cardiac aging: major shareholders in cardiovascular disease enterprises: Part I: aging arteries: a 'set up' for vascular disease. Circulation 2003; 107: 139-146.

14 Somers VK, Dyken ME, Clary MP, Abboud FM. Sympathetic neural mechanisms in obstructive sleep apnoea. J Clin Invest 1995; 96: 1897-1904.

15 Haas DC, Foster GL, Nieto FJ, Redline S, Resnick HE, Robbins JA, Young T, Pickering TG. Age-dependent associations between sleep-disordered breathing and hypertension: importance of discriminating between systolic/diastolic hypertension and isolated systolic hypertension in the Sleep Heart Health Study. Circulation 2005; 111: 614-621.

16 Takahashi K, Chin K, Nakamura H, Morita S, Sumi K, Oga T, Matsumoto H, Niimi A, Fukuhara S, Yodoi J, Mishima M. Plasma thioredoxin, a novel oxidative stress marker, in patients with obstructive sleep apnoea before and after nasal continuous positive airway pressure. Antioxid Redox Signal 2008; 10: 715-726.

17 Takahashi K, Chin K, Akamizu T, Morita S, Sumi K, Oga T, Matsumoto H, Niimi A, Tsuboi T, Fukuhara S, Kangawa K, Mishima M. Acylated ghrelin level in patients with OSA before and after nasal CPAP treatment. Respirology 2008; 13: 810-816.

18 AASM Task Force. Sleep-related breathing disorders in adults: recommendations for syndrome definition and measurement techniques in clinical research. Sleep 1999; 22: 667-689.

19 Johns MW. A new method for measuring daytime sleepiness: the Epworth Sleepiness Scale. Sleep 1991; 14: 540-545.

20 American Society of Hypertension. Recommendations for routine blood pressure measurement by indirect cuff sphygmomanometry. Am J Hypertens 1992; 5: 207-209.
21 Narkiewicz K, Somers VK. The sympathetic nervous system and obstructive sleep apnoea: implications for hypertension. J Hypertens 1997; 15: 1613-1619.

22 Fletcher EC. Sympathetic over activity in the etiology of hypertension of obstructive sleep apnoea. Sleep 2003; 26: 15-19.

23 Davies CWH, Crosby JH, Mullins RL, Barbour C, Davies RJO, Stradling JR. Case-control study of $24 \mathrm{~h}$ ambulatory blood pressure in patients with obstructive sleep apnoea and normal matched control subjects. Thorax 2000; 55: 736-740.

24 Tkacova R, Rankin F, Fitzgerald FS, Floras JS, Bradley TD. Effects of continuous positive airway pressure on obstructive sleep apnea and left ventricular afterload in patients with heart failure. Circulation 1998; 98: 2269-2275.

25 Kaneko Y, Floras JS, Usui K, Plante J, Tkacova R, Kubo T, Ando S, Bradley TD. Cardiovascular effects of continuous positive airway pressure in patients with heart failure and obstructive sleep apnea. N Engl J Med 2003; 348: 1233-1241.

26 Young T, Peppard PE, Gottlieb DJ. Epidemiology of obstructive sleep apnoea: a population health perspective. Am J Respir Crit Care Med 2002; 165: 1217-1239.

27 Young T, Shahar E, Nieto FJ, Redline S, Newman AB, Gottlieb DJ, Walsleben JA, Finn L, Enright P, Samet JM. Predictors of sleep-disordered breathing in community-dwelling adults: the Sleep Heart Health Study. Arch Intern Med 2002; 162: 893-900.

28 Pelletier-Fleury N, Rakotonanahary D, Fleury B. The age and other factors in the evaluation of compliance with nasal continuous positive airway pressure for obstructive sleep apnoea syndrome. A Cox's proportional hazard analysis. Sleep Med 2001; 2 . 225-232.

29 Bixler EO, Vgontzas AN, Lin HM, Calhoun SL, Vela-Bueno A, Kales A. Excessive daytime sleepiness in a general population sample: the role of sleep apnoea, age, obesity, diabetes, and depression. J Clin Endocrinol Metab 2005; 90: 4510-4515.

30 Robinson GV, Smith DM, Langford BA, Davies RJ, Stradling JR. Continuous positive airway pressure does not reduce blood pressure in nonsleepy hypertensive OSA patients. Eur Respir J 2006; 27: 1229-1235.

31 Young T, Finn L, Peppard PE, Szklo-Coxe M, Austin D, Nieto FJ, Stubbs R, Hla KM. Sleep disordered breathing and mortality: eighteen-year follow-up of the Wisconsin sleep cohort. Sleep 2008; 31: 1071-1078.

32 Logan AG, Tkacova R, Perlikowski SM, Leung RS, Tisler A, Floras JS, Bradley TD. Refractory hypertension and sleep apnoea: effect of CPAP on blood pressure and baroreflex. Eur Respir J 2003; 21: 241-247.

33 Martinez-Garcia MA, Gomez-Aldaravi R, Soler-Cataluna JJ, Martinez TG, BernacerAlpera B, Roman-Sanchez P. Positive effect of CPAP treatment on the control difficultto-treat hypertension. Eur Respir J 2007; 29: 951-957.

34 Verdecchia P, Reboldi G, Porcellati C, Schillaci G, Pede S, Bentivoglio M, Angeli F, Norgiolini S, Ambrosio G. Risk of cardiovascular disease in relation to achieved office and ambulatory blood pressure control in treated hypertensive subjects. J Am Coll Cardiol 2002; 39: 878-885.

35 Sega R, Facchetti R, Bombelli M, Cesana G, Corrao G, Grassi G, Mancia G. Prognostic value of ambulatory and home blood pressures compared with office blood pressure in the general population: follow-up results from the Pressioni Arteriose Monitorate e Loro Associazioni (PAMELA) study. Circulation 2005; 111: 1777-1783.

36 Monasterio C, Vidal S, Duran J, Ferrer M, Carmona C, Barbé F, Mayos M, Gonzalez-Mangado N, Juncadella M, Navarro A, Barreira R, Capote F, Mayoralas LR, Peces-Barba G. Alonso J, Montserrat JM. Effectiveness of continuous positive airway pressure in mild sleep apnea-hypopnea syndrome. Am J Respir Crit Care Med 2001; 164: 939-943.

37 Mansfield DR, Gollogly NC, Kaye DM, Richardson M, Bergin P, Naughton MT. Controlled trial of continuous positive airway pressure in obstructive sleep apnea and heart failure. Am J Respir Crit Care Med 2004; 169: 361-366.

38 MacMahon S, Peto R, Cutler J, Collins R, Sorlie P, Neaton J, Abbott R, Godwin J, Dyer A, Stamler J. Blood pressure, stroke, and coronary heart disease. Part 1, prolonged differences in blood pressure: prospective observational studies corrected for the regression dilution bias. Lancet 1990; 335: 765-774. 